\title{
Clopidogrel plus aspirin was effective but increased bleeding in acute coronary syndromes without ST-segment elevation
}

\author{
The Clopidogrel in Unstable Angina to Prevent Recurrent Events Trial Investigators. Effects of clopidogrel in addition to \\ aspirin in patients with acute coronary syndromes without ST-segment elevation. N Engl J Med 2001 Aug \\ 16;345:494-502. \\ QUESTION: What is the efficacy and safety of early and long term use of clopidogrel \\ plus aspirin and aspirin alone in patients with acute coronary syndromes without \\ ST-segment elevation?
}

\section{Design}

Randomised (allocation concealed*), blinded \{patients, healthcare providers, data collectors, outcome assessors, monitoring committee, statisticians, and manuscript writers $\} \nmid *$ * placebo controlled trial with 12 months of follow up (Clopidogrel in Unstable Angina to Prevent Recurrent Events [CURE] Trial).

\section{Setting}

482 centres in 28 countries.

\section{Patients}

12562 patients (mean age 64 y, 62\% men) who were admitted to hospital within 24 hours of symptom onset, had either electrocardiographic changes or elevated concentrations of cardiac enzymes, and did not have ST-segment elevation. Exclusion criteria were contraindications to antithrombotic or antiplatelet treatment, high risk for bleeding or severe heart failure, oral anticoagulant use, coronary revascularisation in the previous 3 months, or intravenous glycoprotein $\mathrm{Ilb} / \mathrm{III}$ receptor inhibitors in the previous 3 days. Follow up was $99.9 \%$

\section{Intervention}

6259 patients were allocated to an immediate loading dose of oral clopidogrel $300 \mathrm{mg}$, followed by $75 \mathrm{mg}$ /day for 3 to 12 months; 6303 patients were allocated to placebo. All patients received aspirin 75-325 mg/day.

\section{Main outcome measures}

Main outcomes were a composite of death from cardiovascular causes, non-fatal myocardial infarction (MI), or stroke and a composite of death from cardiovascular causes, non-fatal MI, stroke, or refractory ischaemia. Safety outcomes included major and minor bleeding.

\section{Main results}

Analysis was by intention to treat. Patients in the clopidogrel group had lower rates of the 2 composite outcomes $(\mathrm{p}<0.001)$, but higher rates of major and minor bleeding $(\mathrm{p}<0.001)$ than did patients in the aspirin alone group (table).

\section{Conclusion}

Clopidogrel plus aspirin was more effective than aspirin alone in patients with acute coronary syndromes without ST-segment elevation, but it increased bleeding.

*See glossary.

†Information provided by author.

\begin{abstract}
Sources of funding: Sanofi-Synthelabo and Bristol-Myers Squibb.

For correspondence: Dr S Yusuf, Hamilton General Hospital, Hamilton, Ontario, Canada.

yusuf@mcmaster.ca.
\end{abstract}

Clopidrogrel plus aspirin v aspirin alone for acute coronary syndromes without ST-segment elevation

\begin{tabular}{|c|c|c|c|c|}
\hline $\begin{array}{l}\text { Outcomes at } 12 \\
\text { months }\end{array}$ & $\begin{array}{l}\text { Clopidrogrel } \\
\text { plus aspirin }\end{array}$ & $\begin{array}{l}\text { Aspirin } \\
\text { alone }\end{array}$ & $\operatorname{RRR}(95 \%$ Cl) & NNT (CI) \\
\hline Composite 1 & $9 \%$ & $11 \%$ & $20 \%(10$ to 28$)$ & 48 (32 to 96$)$ \\
\hline \multirow[t]{2}{*}{ Composite 2} & $17 \%$ & $19 \%$ & $14 \%(6$ to 21$)$ & 44 (28 to 104) \\
\hline & & & RRI (Cl) & NNH (Cl) \\
\hline Major bleeding & $3.7 \%$ & $2.7 \%$ & $38 \%(13$ to 67$)$ & 100 (62 to 252$)$ \\
\hline Minor bleeding & $5.1 \%$ & $2.4 \%$ & $112 \%(75$ to 156$)$ & 37 (30 to 49$)$ \\
\hline
\end{tabular}

tComposite 1 = composite of death from cardiovascular causes, non-fatal myocardial infarction (MI), or stroke; composite 2 = death from cardiovascular causes, non-fatal MI, stroke, or refractory ischaemia. Other abbreviations defined in glossary; RRR, RRI, NNT, NNH, and Cl calculated from data in article.

\section{COMMENTARY}

The findings of the CURE trial are impressive, showing a statistically significant reduction in the primary composite end point of death from cardiovascular causes, non-fatal MI, or stroke in patients treated with clopidogrel and aspirin. More than that, the incidence of Q-wave MI, which is unarguably an important adverse outcome of acute coronary syndromes, was also substantially decreased. This benefit was not observed in previous trials ${ }^{1-3}$ that assessed other antiplatelet strategies for acute coronary syndromes.

Increased major and minor bleeding in patients who received clopidogrel plus aspirin is an important concern. $17 \%$ of patients had coronary artery bypass grafting $(\mathrm{CABG})$. When $\mathrm{CABG}$ was done within 5 days of clopidogrel treatment $(\mathrm{n}=912)$, the incidence of major bleeding was higher than in control group patients $(9.6 \% v 6.3 \%, \mathrm{p}=0.06)$. In the 910 patients who had surgery $>5$ days after stopping clopidogrel, no additional risk for bleeding was found. Thus, at least some bleeding complications can be prevented by delaying surgery. With this precaution in mind, the use of early and long term clopidogrel and aspirin in patients with acute coronary syndromes and clinical characteristics similar to those of the patients enrolled in the CURE trial is appropriate. Patients who do and do not have revascularisation should benefit.

The addition of clopidogrel to the regimen of such patients will increase expenses by approximately $\$ 1500 /$ patient/year. The increased costs may be offset by a reduction in expensive complications. A cost-effectiveness analysis is underway. The utility of continuing clopidogrel treatment beyond 1 year requires additional study.

Itzhak Kronzon, MD

Frederick Feit, MD

New York University School of Medicine, New York, New York, USA

1 Pursuit Trial Investigators. Inhibition of platelet glycoprotein IIb/IIIa with eptifibatide in patients with acute coronary syndromes. N Engl J Med 1998;339:436-48.

2 Simoons ML and the GUSTO IV-ACS Investigators. Effect of glycoprotein IIb/IIIa receptor blocker abciximab on outcome in patients with acute coronary syndromes without early coronary revascularization: the GUSTO IV-ACS randomized trial. Lancet 2001;357:1915-24.

3 Platelet Receptor Inhibition in Ischemic Syndrome Management in Patients Limited by Unstable Signs and Symptoms (PRISM-PLUS) Investigators. Inhibition of the platelet glycoprotein IIb/IIIa receptor with tirofiban in unstable angina and non Q-wave acute myocardial infarction. $N$ Engl J Med 1998;338:1488-97. 